\title{
DENSIDADES DO TERRITÓRIO EM ANÁPOLIS - GOIÁS: notas sobre o trevo sul da Avenida Brasil
}

\section{DENSITIES OF THE TERRITORY IN ANÁPOLIS - GOIÁS: notes on the roundabout south of Avenida Brasil}

\section{DENSIDADES DEL TERRITORIO EN ANÁPOLIS - GOIÁS: notas sobre la rotonda sur de Avenida Brasil}

\author{
Hamilton Matos Cardoso Júnior \\ Universidade Federal da Paraíba - UFPB \\ E-mail: <hjuniorgo@hotmail.com>.
}

\begin{abstract}
RESUMO
Anápolis é uma das principais cidades industriais da região Centro-Oeste do Brasil. Estão sediadas em seu Distrito Agroindustrial importantes empresas de diversos segmentos. Este trabalho tem como objetivo analisar a presença da densidade técnica e normativa que permeiam a questão do habitar na cidade média, tendo como objeto de estudo uma área traçada a partir do viaduto da saída sul da cidade de Anápolis, onde se concentra a maior parte das indústrias e outras grandes empresas, como atacadistas e transportadoras. Para isso, utilizou-se como principal metodologia o trabalho de campo. Foi traçado um raio de $4 \mathrm{~km} \mathrm{a}$ partir do referido viaduto. Dentro dessa área foram identificados os principais aparelhos urbanos responsáveis pelas conexões de Anápolis com outros pontos do território. Posteriormente, foi feito um levantamento bibliográfico a autores para análise da área de estudo, discutindo sobre a densidade técnica e normativa a luz das teorias e do trabalho de campo. Conclui-se com esta pesquisa que em Anápolis, mais especificamente a área analisada, a questão do habitar ocorre em meio à cidade que intensifica a divisão social do trabalho, que se comunica não mais apenas em redes, mas em um sistema urbano.
\end{abstract}

Palavras-chave: Consumo. Habitar. Objetos Técnicos. Sistema Urbano.

\begin{abstract}
Anápolis is one of the main industrial cities of the Central-West region of Brazil. Are based on your District Agroindustrial companies of various sectors. This work aims to present analysis on the presence of technical and normative density in Annapolis that permeate the issue of dwell in the city average, having as object of study an area drawn from the overpass the South exit of this city, where most of the focus on industries and companies of other branches, such as wholesalers and carriers. For this, we use as primary field research
\end{abstract}


methodology. It was a $4 \mathrm{~km}$ radius from the above-mentioned viaduct. In this area have been identified the main urban devices responsible for the expansion of Anápolis in different scales. It was subsequently made a bibliographical survey the authors for analysis of the object of study. Concludes with this research in Anápolis, more specifically the area considered the issue of dwell occurs in the middle of the city that intensifies the social division of labor, that communicates not only in networks, but in an urban system.

Keywords: Consumption. Dwell. Technical Objects. Urban System.

\section{RESUMEN}

Anápolis es una de las principales ciudades industriales de la región centro-oeste de Brasil. Se basan en sus compañías del distrito Agroindustrial de diversos sectores. Este trabajo tiene como objetivo presentar análisis sobre la presencia de densidad técnica y normativa en Anápolis que permean la cuestión de lo vivir en el medio de la ciudad, teniendo como objeto de estudio una superficie del paso a desnivel de la salida sur de esta ciudad, donde la mayoría del foco en las industrias y empresas de otras ramas, tales como mayoristas y transportistas. Para ello, utilizamos como metodología de la investigación de campo principal. Era un radio de $4 \mathrm{~km}$ desde el mencionado viaducto. En esta área han sido identificados los dispositivos urbanos principales responsables de la expansión de Anápolis en diferentes escalas. Posteriormente realizó una bibliográfica los autores para el análisis del objeto de estudio de la encuesta. Concluye con esta investigación en Anápolis, más que específicamente la zona considera que el tema de la detención se produce en medio de la ciudad, que se intensifica la división social del trabajo, que se comunica no sólo en las redes, pero en un sistema urbano.

Palabras clave: Consumo. Vivir. Objetos técnicos. Sistema urbano.

\section{INTRODUÇÃO}

Esta pesquisa tem como objetivo analisar a densidade técnica e normatiza a partir de um ponto traçado na área urbana do município de Anápolis - Goiás, conduzido a discussão para a questão do "habitar" na cidade média industrial. Para isso, identificaram-se os equipamentos urbanos, intervenções de infraestrutura e o uso do território a partir do viaduto sul da cidade, mais especificamente na interseção entre a Avenida Brasil-Sul e a rodovia BR 060/153 e GO - 330, destacando nessa dinâmica urbana as relações do homem na produção do espaço na cidade média industrial.

Partiu-se da concepção do espaço urbano produzido e reproduzido com base em três conceitos: densidade técnica; densidade normativa e circuitos espaciais de produção. Os passos metodológicos foram divididos em três momentos: o primeiro com a análise de imagens de satélite e mapas da área de estudo com intuito de traçar um raio para análise, bem como levantamento bibliográfico aos conceitos previamente determinados para análise da Revista Cerrados, Montes Claros/MG, v.17, n. 2, p. 265-289, jul./dez.-2019. 
CARDOSO JUNIOR, H. M.

Densidades do território em Anápolis - Goiás: notas sobre o trevo sul da Avenida Brasil

área estudada; no segundo momento procedeu-se à realização do trabalho de campo, momento no qual se percorreu de carro o raio traçado e empreendendo a análise com base nos conceitos definidos; por fim, no terceiro momento realizaram-se as análises a luz das teorias pesquisadas.

Este trabalho está dividido em cinco seções, a contar com esta introdução. Nesse sentido, a segunda seção traz a caracterização e localização da área analisada; na terceira seção é realizada uma exposição das impressões obtidas durantes as análises empíricas do trabalho de campo; a quarta seção traz uma análise da densidade técnica e normativa, sustentada pelas teorias pesquisadas, e sua relação com a produção do espaço urbano e conexão do município com outros pontos do Território; por fim, a quinta e última seção traz as considerações finais deste estudo.

\section{CARACTERIZAÇÃO E LOCALIZAÇÃO DA ÁREA ESTUDADA}

Uma pesquisa de campo tem como intuito percorrer espaços muitas vezes já visitados pelos sujeitos em seu cotidiano. A empreitada se dá na investigação crítica desse espaço, lançando um olhar diferente sobre determinada realidade por meio do conhecimento já acumulado - conceitos, escalas, categorias, etc. -, buscando compreendê-lo criticamente (ATUNNES; MELLO; ARRAIS, 2007).

Entretanto, a escolha metodológica de uma pesquisa de campo é crucial para o olhar crítico da realidade. O pesquisador deve eleger cuidadosamente seus passos metodológicos antes de iniciar seu trabalho de campo. Como apontam Antunes, Mello e Arrais (2007, p. 145): "Pensar em um trabalho de campo, planejá-lo não é uma tarefa fácil. Por menor que seja a dimensão do espaço e sua densidade histórica é imprescindível planejálo, o que significa avaliar os recursos e o roteiro com disposição e abertura de espírito".

Portanto, definir o objeto de pesquisa do trabalho de campo, bem como a metodologia empregada para analisá-lo, constitui um processo importante para que o pesquisador consiga alcançar os objetivos previamente estabelecidos. Como ratifica Brandão (2000), a "construção do objeto" refere-se à capacidade de optar pela alternativa metodológica que mais se adequa a sua análise.

O município de Anápolis, Figura 1, localiza-se no estado de Goiás (região CentroOeste do Brasil) na Microrregião de mesmo nome. Está a 50 km da cidade de Goiânia (capital 
CARDOSO JUNIOR, H. M.

Densidades do território em Anápolis - Goiás: notas sobre o trevo sul da Avenida Brasil

estadual) e a $150 \mathrm{~km}$ de Brasília (capital federal). É ligada a essas duas cidades pela rodovia BR-060/153 e compõe com essas duas capitais o chamado Eixo Goiânia- Anápolis-Brasília.

Anápolis ocupa a segunda posição entre os municípios mais importantes do estado de Goiás, atrás apenas da capital: Goiânia. Segundo dados do IBGE (IBGE, 2016), o Produto Interno Bruto desse município, em $2015^{1}$, era de R $\$ 13.3$ bilhões. Sua população, de acordo com o censo (IBGE, 2010), atingiu a marca de 334.613 habitantes, o que coloca esse município como o terceiro mais populoso de Goiás e o sexto da região Centro-Oeste. A estimativa populacional para 2015 era de 366.592 habitantes (IBGE, 2016).

Figura 1: Localização do município de Anápolis - Goiás

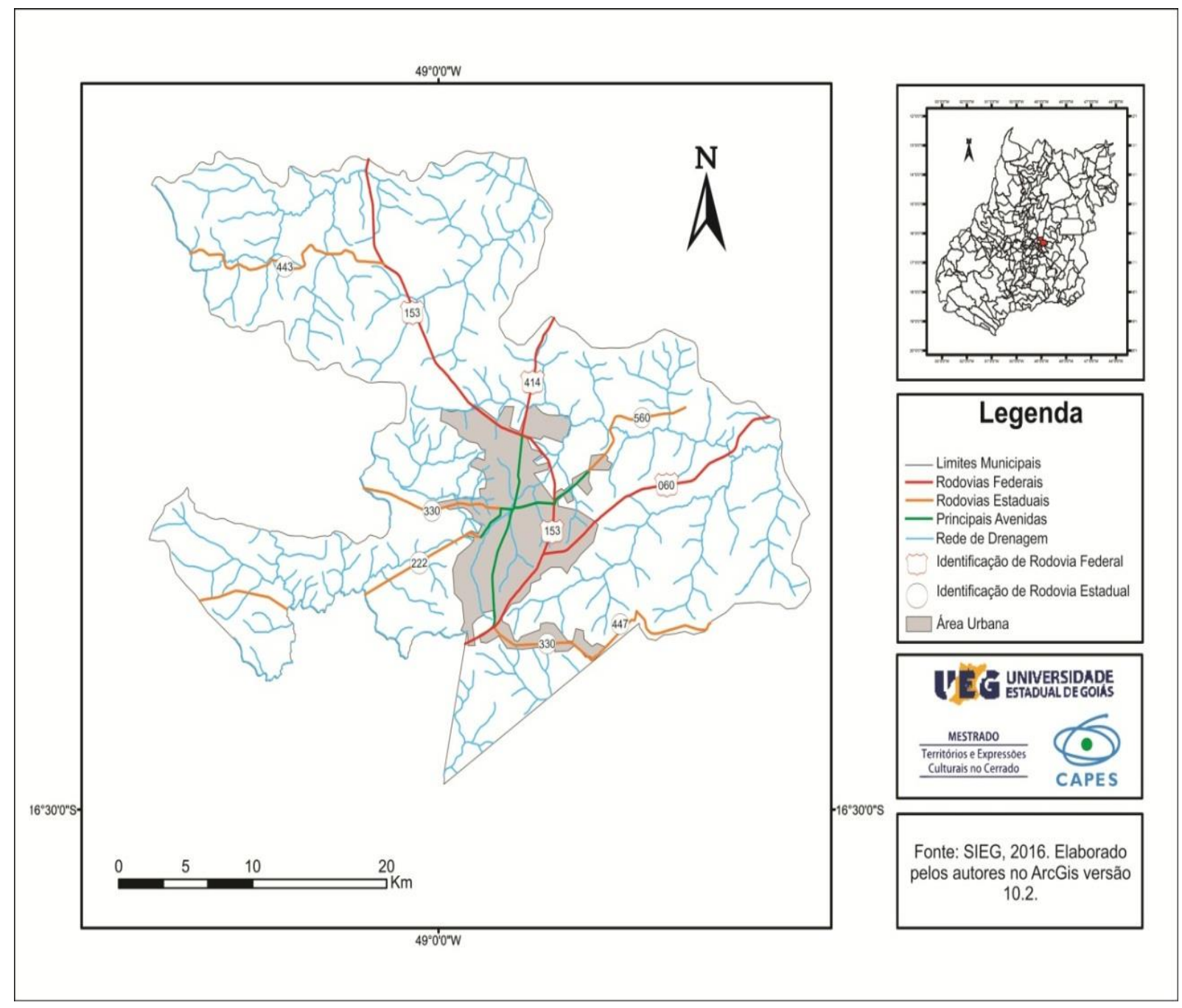

Fonte: SIEG, 2016.

\footnotetext{
${ }^{1}$ O dados socioeconômicos a seguir referem-se ao ano de 2015, ano da realização do trabalho de campo.
} 
CARDOSO JUNIOR, H. M.

Densidades do território em Anápolis - Goiás: notas sobre o trevo sul da Avenida Brasil

Sua localização territorial estratégica aliada a políticas públicas de crescimento econômico fizeram com que o município se tornasse em um importante centro de serviços e um dos principais polos industriais da região Centro-Oeste. Anápolis concentra grande número de indústrias, a maioria no Distrito Agroindustrial, no qual se destaca a presença do setor automobilístico, farmacêutico e alimentício.

Por outro lado, o município possui um setor de serviços bem dinâmico, com comércio diversificado, além do grande número de importantes empresas atacadistas e de logística. O setor de serviços e a indústria exercem relevante importância na economia desse município. Juntos os setores representaram 87,24\% do Valor Adicionado do PIB de Anápolis em 2015 (IBGE, 2016). Já a agropecuária representou apenas 0,45\%, fator que explica as altas taxas de urbanização. No ano de $2010,98,24 \%$ da população vivia na zona urbana desse município e 1,76 na zona rural (IBGE, 2010).

Pensando no papel logístico da produção e transporte de mercadorias desse município, elegeu-se como objeto de estudo o viaduto da saída sul da cidade, com intuito de analisar o uso e ocupação dessa área, pensado a questão do habitar e relacionando-a com a presença da densidade técnica e normativa nessa localidade. Para isso, tendo como referência o viaduto, traçou-se um raio de $4 \mathrm{~km}$, sendo essa a área de análise nesta pesquisa (Figura 2).

O viaduto está situado a uma distância de $7,6 \mathrm{~km}$ do centro da cidade e é a principal entrada para o Distrito Agroindustrial. O raio traçado como área de estudo concentra grande contingente populacional, em sua maioria de trabalhadores das indústrias ou no centro da cidade. Todavia, encontram-se alguns condomínios horizontais fechados nessa área, todos ao longo da Avenida Brasil Sul ${ }^{2}$, principal eixo viário da cidade, indicando uma ocupação também de uma faixa de população com alta renda.

\footnotetext{
${ }^{2}$ A Avenida Brasil-Sul juntamente com a Avenida Brasil-Norte forma um importante eixo em linha reta que traça a cidade de Anápolis de norte a sul, sendo a avenida de maior fluxo da cidade, desempenhando importante papel no transporte de pessoas e mercadorias. Ao término de ambas as avenidas há viadutos que as integram com rodovias federais e estaduais. $\mathrm{O}$ trajeto das duas avenidas de um ponto ao outro totaliza $12,3 \mathrm{~km}$.
} 
CARDOSO JUNIOR, H. M.

Densidades do território em Anápolis - Goiás: notas sobre o trevo sul da Avenida Brasil

Figura 2: Localização da área de estudo

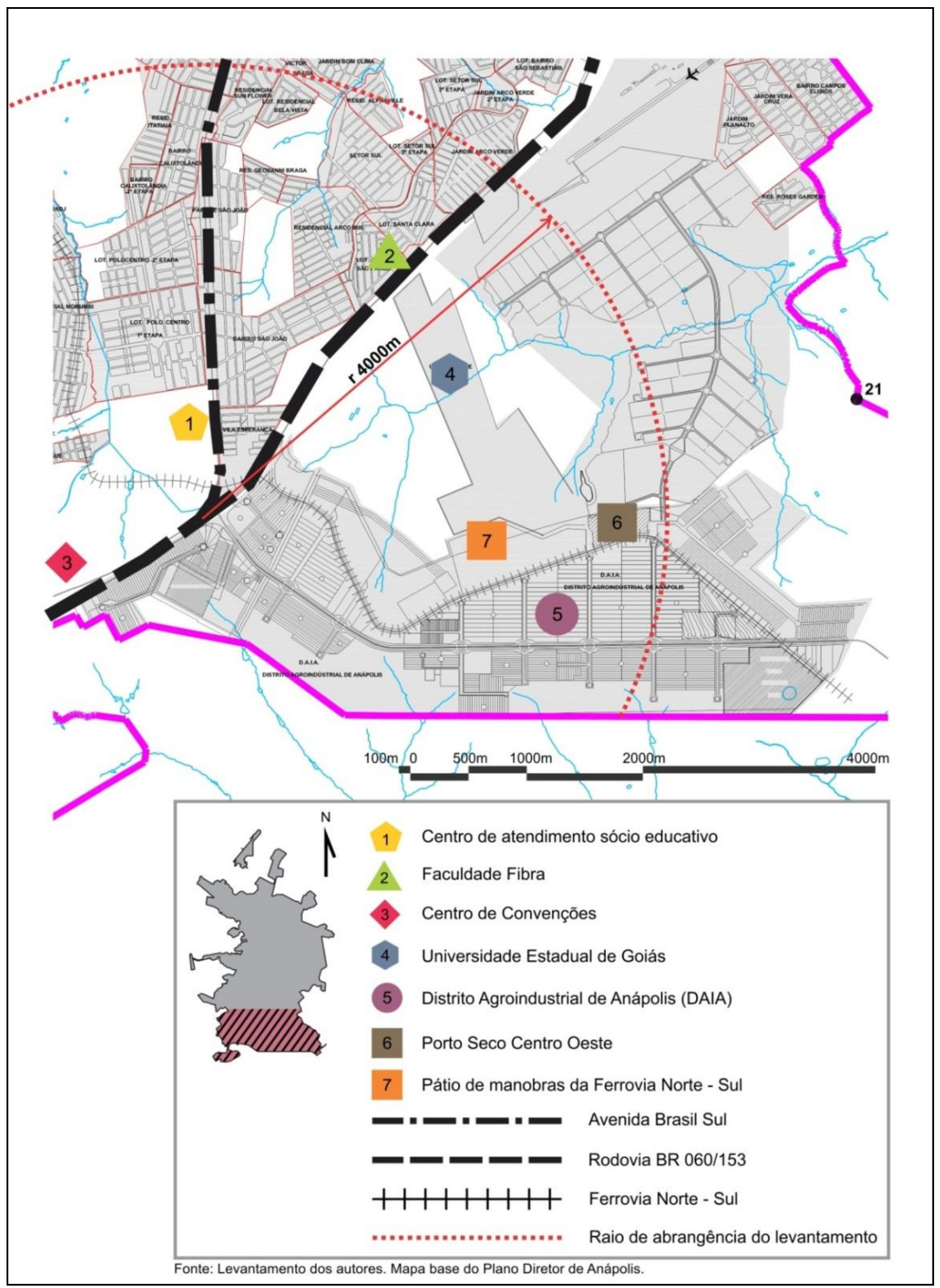

Fonte: Levantamento dos autores.

Revista Cerrados, Montes Claros/MG, v.17, n. 2, p. 265-289, jul./dez.-2019. 
Densidades do território em Anápolis - Goiás: notas sobre o trevo sul da Avenida Brasil

A obra do viaduto (Figura 3) foi iniciada e inaugurada no ano de 2014, sendo implantada com recursos do governo federal. Representa um importante ponto de logística para a cidade de Anápolis e para o estado de Goiás por localizar-se às margens do Distrito Agroindustrial de Anápolis (DAIA), bem como por interligar duas grandes capitais do Centro-Oeste: Goiânia e Brasília. A obra representa a concretização dos interesses do empresariado industrial. Juntamente com as rodovias que o entrelaçam, concebe o conjunto de densidades técnicas que permitem e garantem os fluxos de mercadorias e pessoas nas diferentes direções do país.

Figura 3: Viaduto da saída sul de Anápolis, 2015

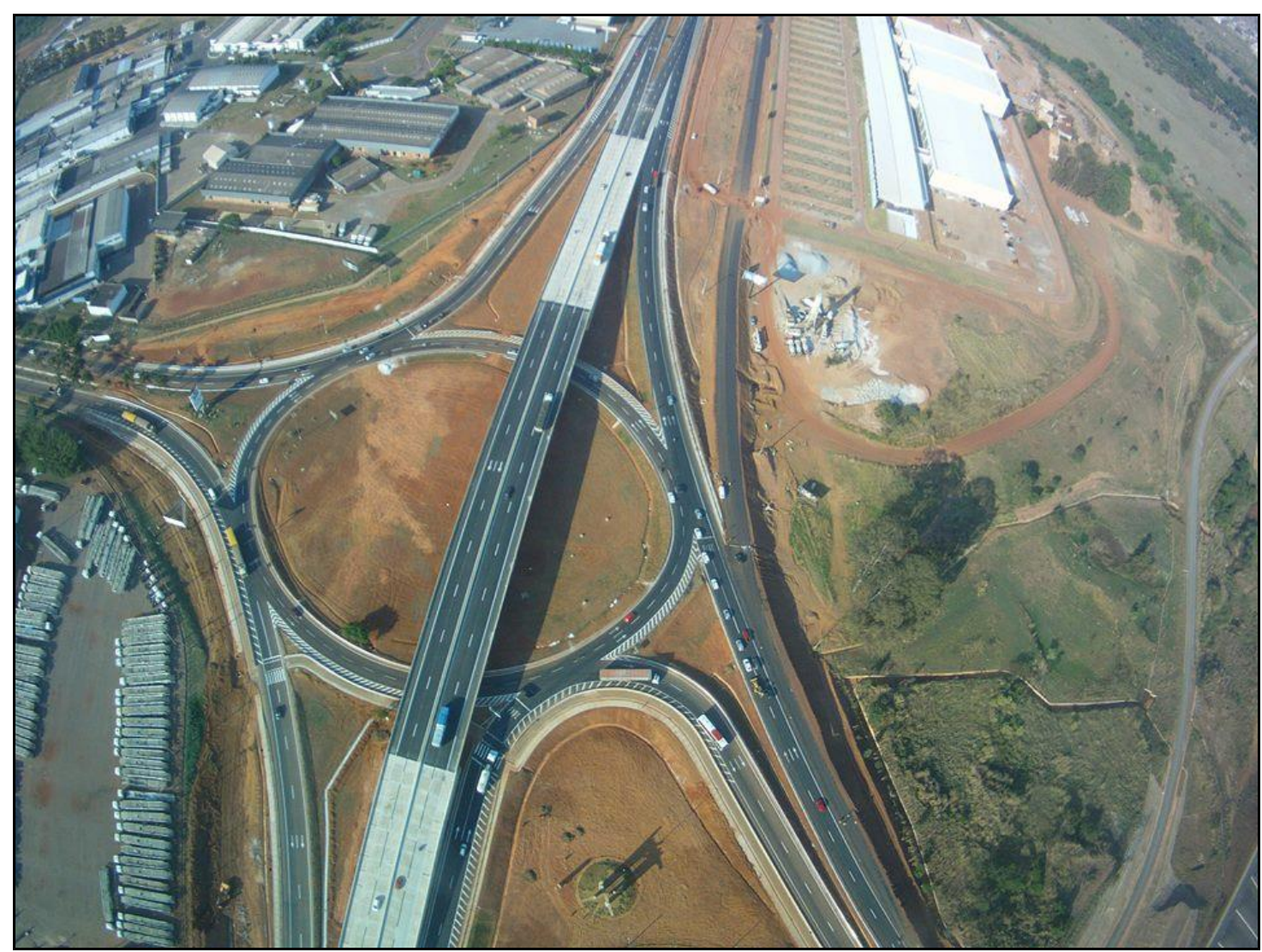

Fonte: José Carlos Potenciano. Disponível em:

<http://www.skyscrapercity.com/showthread.php?t=1198995\&page=700>. Acessado em: outubro de 2015.

Fazem-se presentes na área de estudo importantes equipamentos que conectam o território na escala regional, nacional e global, bem como infraestruturas em construção que ampliarão o papel do município de Anápolis no setor logístico do Brasil e na oferta de serviços em Goiás, sendo eles: Centro de Atendimento Socioeducativo de Anápolis; Centro 
CARDOSO JUNIOR, H. M.

Densidades do território em Anápolis - Goiás: notas sobre o trevo sul da Avenida Brasil

de Convenções de Anápolis; Universidade Estadual de Goiás; Distrito Agroindustrial de Anápolis (DAIA); Porto Seco Centro Oeste e Pátio de Manobras da Ferrovia Norte-Sul.

Os efeitos multiplicadores do crescimento industrial afetam toda a área nesse ponto da cidade, refletido na expansão e adensamento urbano com a criação de conjuntos habitacionais e na construção de hotéis ao longo dos últimos quilômetros da Avenida BrasilSul. Devido à concentração industrial, a área contra grande parte dos postos de trabalho do município.

Na próxima seção são apresentadas as impressões a respeito do trabalho de campo realizado na área delimitada, destacando cada um dos equipamentos selecionados para essa pesquisa, apontando sua importância e papel para a produção do espaço urbano e conexão de Anápolis na escala nacional, regional e local.

\section{IMPRESSÕES DA ÁREA DE ESTUDO OBTIDAS NO TRABALHO DE CAMPO}

O trabalho de campo foi realizado no dia 20 de novembro de 2015 - sexta-feira -, no período da manhã entre as 9:00 e 12:00 horas. O percurso foi realizado de carro. Percorreu-se quatro eixos (Figura 4), todos convergentes ao viaduto, onde ocorreram paradas nos principais equipamentos e as estruturas já mencionadas.

$\mathrm{O}$ primeiro eixo refere-se à Avenida Brasil Sul. A visita de campo foi iniciada na altura do Condomínio Residencial Fechado Sun Flower, a cerca de 3,8 km do viaduto. Durante o percurso pôde-se perceber que esse trecho da avenida tem recebido os efeitos multiplicadores do crescimento industrial do Distrito Agroindustrial de Anápolis.

Analisando imagens de satélite no período de 2000 a 2015, percebeu-se a expressiva expansão urbana nas proximidades desse eixo, dentro do raio de análise, caracterizada pela horizontalidade das construções. Recentemente, o eixo tem iniciado seu processo de verticalização com a construção de hotéis que servem, principalmente, a usuários que mantêm relação com o DAIA e com os atacadistas presentes nessa avenida, fomentando o chamado turismo de negócios. 
CARDOSO JUNIOR, H. M.

Densidades do território em Anápolis - Goiás: notas sobre o trevo sul da Avenida Brasil

Figura 4: Eixos percorridos no trabalho de campo - Anápolis (GO)

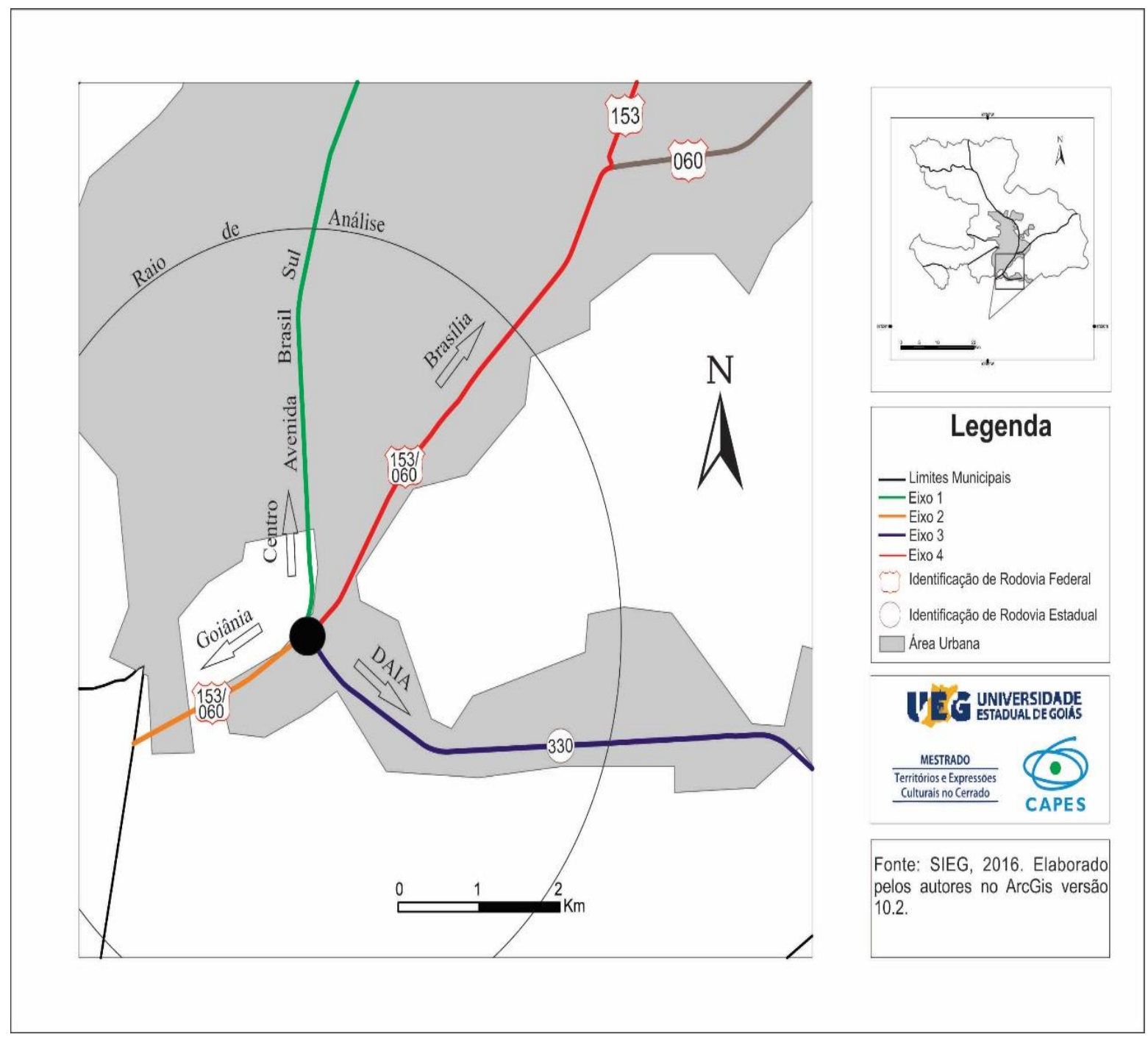

Fonte: SIEG, 2016.

Recentemente, o eixo tem iniciado seu processo de verticalização com a construção de hotéis que servem, principalmente, a usuários que mantêm relação com o DAIA e com os atacadistas presentes nessa avenida, fomentando o chamado turismo de negócios. Do mesmo modo, percebe-se que esse ponto da avenida tem atraído investimentos ligados a revendedoras de automóveis e caminhões (Figura 5), que têm deixado outros pontos da cidade para instalarem-se ao longo desse trecho. Esse movimento faz parte da estratégia dessas empresas em se tornarem visíveis ao consumidor, já que essa avenida é importante corredor de transporte de trabalhadores, bem como devido à presença de grandes terrenos desocupados e áreas de fácil estacionamento. 
CARDOSO JUNIOR, H. M.

Densidades do território em Anápolis - Goiás: notas sobre o trevo sul da Avenida Brasil

Figura 5: Instalações das Revendedoras Kia Motors, Suzuki, Chevrolet e do Confort Hotel -

$$
\text { Anápolis (GO) - } 2015
$$

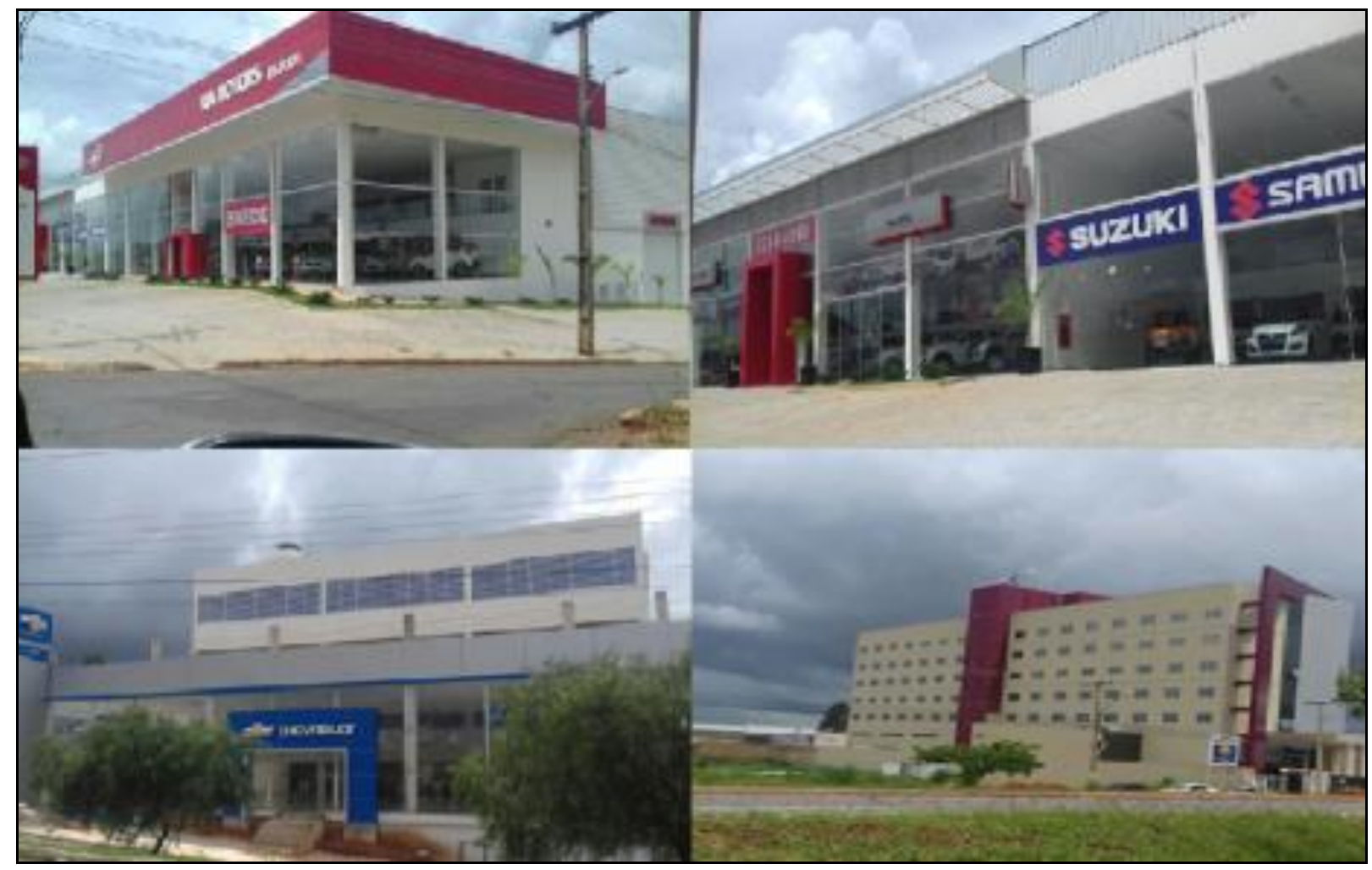

Fonte: Fotos tiradas pelos autores.

Outros segmentos de serviços também se estruturam nesse trecho, como empresas especializadas em dar apoio a outros setores, a citar as transportadoras, lojas de peças de veículos (pneus, ferragistas, baterias, etc) e oficinas, bem como atacadistas de grande porte. Como promessa de ampliação da articulação regional dessa área com o estado de Goiás, também está sendo construído, nas proximidades do viaduto, o Centro Socioeducativo de Anápolis (CASE) $)^{3}$.

Segundo a Segplan (2016), o CASE terá capacidade para atender a 80 jovens em regime de internação permanente e provisória. Acolherá menores de idade em recuperação social de toda a região, principalmente dos municípios da Microrregião de Anápolis. Esse empreendimento amplia as conexões desse município no plano regional, expandindo o papel desse ponto da cidade.

$\mathrm{O}$ segundo eixo refere-se à $\mathrm{BR}$ - 060/153 sentido sul, partindo do viaduto. $\mathrm{O}$ canteiro de obras do Centro de Convenções de Anápolis (Figura 6) foi o principal ponto de

\footnotetext{
${ }^{3}$ Inaugurado em abril de 2018.
}

Revista Cerrados, Montes Claros/MG, v.17, n. 2, p. 265-289, jul./dez.-2019. 
CARDOSO JUNIOR, H. M.

Densidades do território em Anápolis - Goiás: notas sobre o trevo sul da Avenida Brasil

parada. Esse espaço, ainda em construção ${ }^{4}$, apresenta-se como promessa ao capital empresarial de Anápolis, servindo como centro de reuniões, eventos e feiras, articulando ainda mais Anápolis com o estado e com o país.

Figura 6: Construção do Centro de Convenções de Anápolis (GO) - 2015

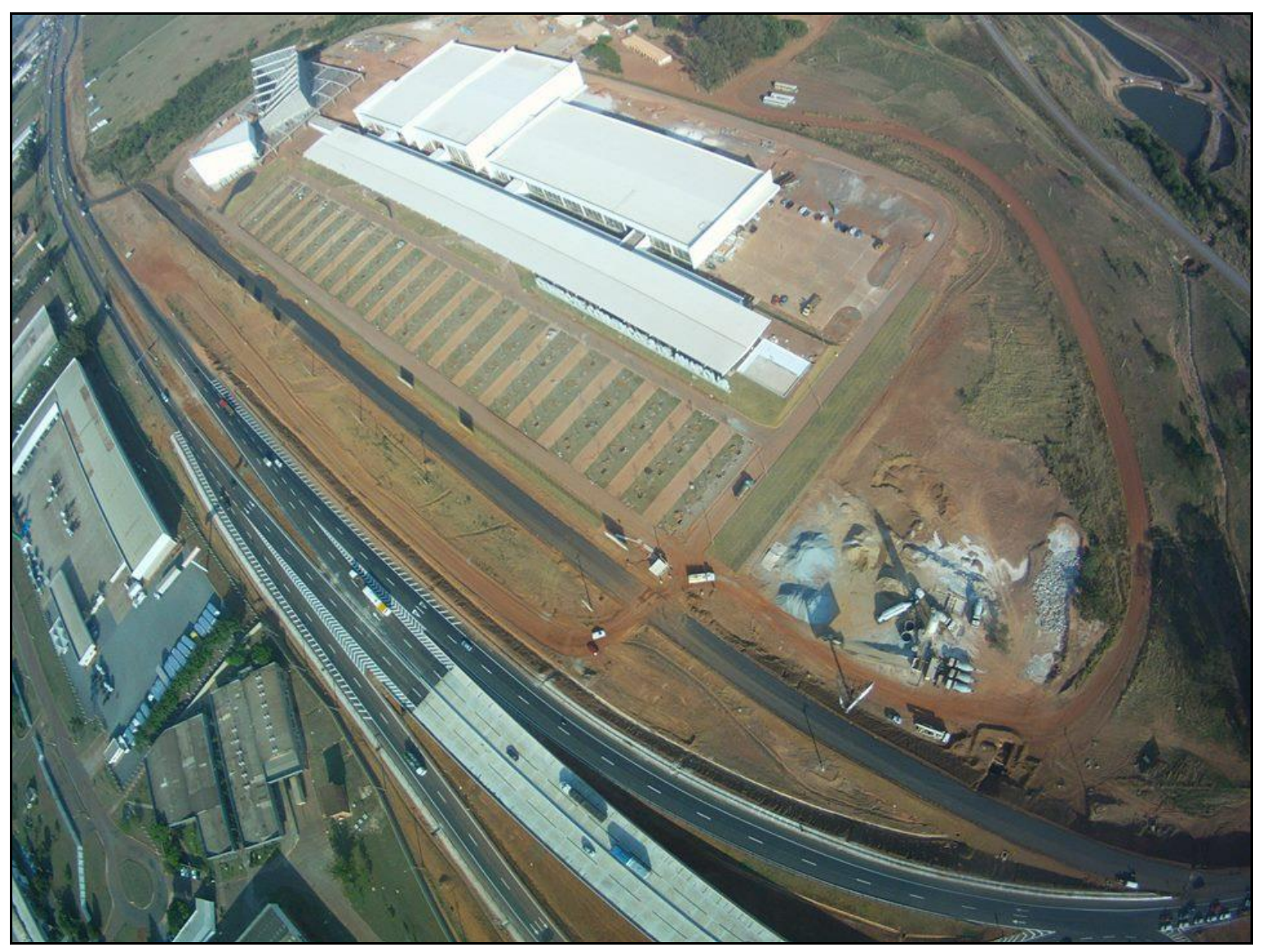

Fonte: José Carlos Potenciano. Disponível em:

<http://www.skyscrapercity.com/showthread.php?t=1198995\&page=700>. Acessado em: outubro de 2015.

Após o Centro de Convenções, pôde-se perceber, dentro do raio de análise, que a existência de bairros e as indústrias diminuem. Esse fato é explicado devido ao limite territorial do município. No lado leste da rodovia há a presença de algumas fazendas e chácaras e do lado oeste a presença de algumas indústrias, transportadoras e postos de combustíveis.

$\mathrm{O}$ terceiro eixo refere-se à $\mathrm{GO}$ - 330, partindo do viaduto. A rodovia é uma importante via que integra o Distrito Agroindustrial de Anápolis (DAIA), possuindo, às suas margens, indústrias de vários segmentos. O DAIA (Figura 7) é a principal estrutura que

\footnotetext{
${ }^{4}$ Inaugurado em abril de 2018.
}

Revista Cerrados, Montes Claros/MG, v.17, n. 2, p. 265-289, jul./dez.-2019. 
CARDOSO JUNIOR, H. M.

Densidades do território em Anápolis - Goiás: notas sobre o trevo sul da Avenida Brasil

dinamiza e atrai investimentos em toda a área analisada. Segundo a Companhia de Desenvolvimento Econômico de Goiás (2015), o distrito possui 108 empresas em sua maioria multinacionais e transnacionais.

Figura 7: Parte do Distrito Agroindustrial de Anápolis (GO) - 2015

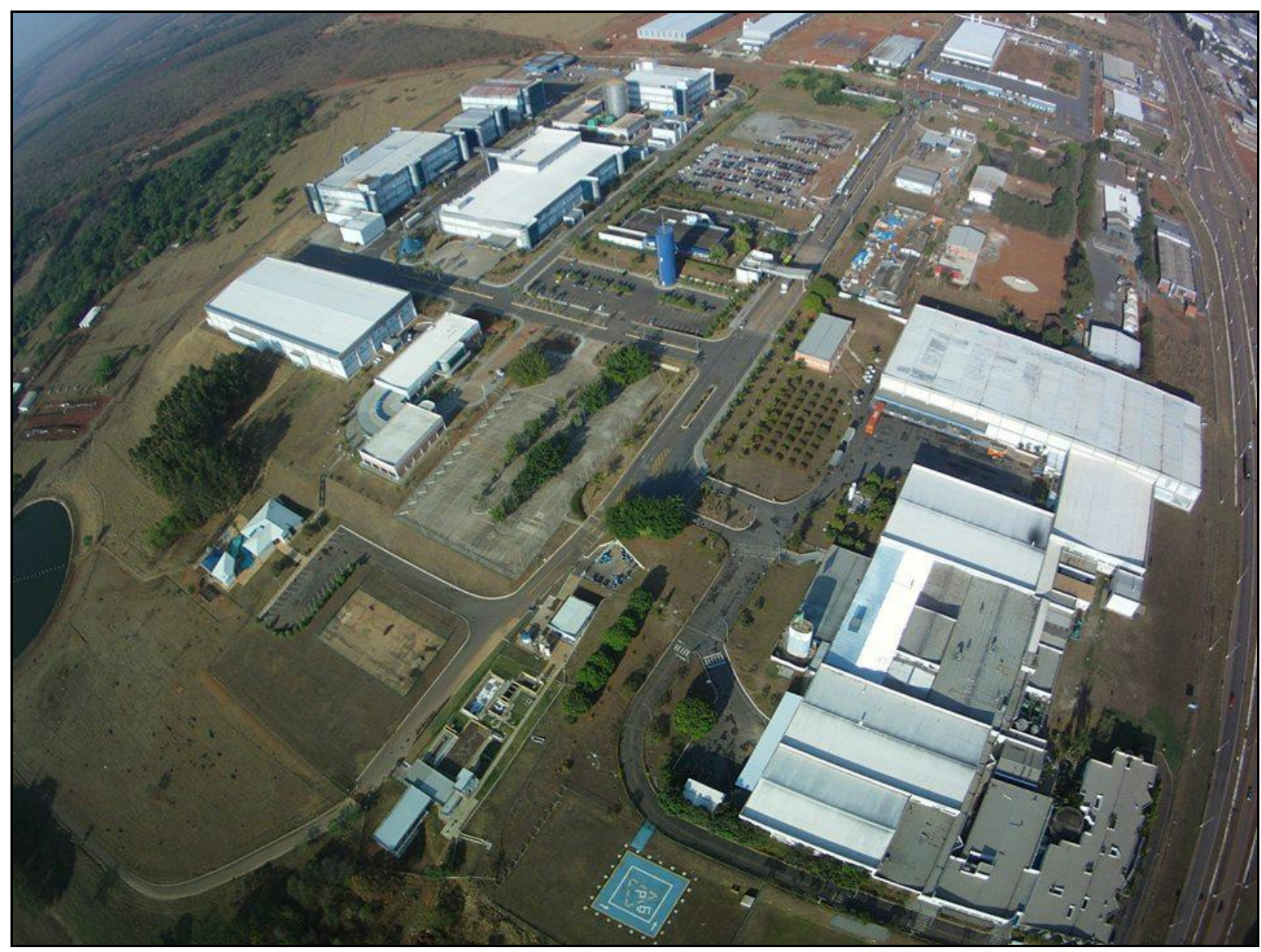

Fonte: José Carlos Potenciano. Disponível em:

<http://www.skyscrapercity.com/showthread.php?t=1198995\&page=700>. Acessado em: outubro de 2015.

Seguiu-se pela rodovia, dentro do raio de análise, e entrando na Viela VP-6E até o Porto Seco Centro-Oeste (Figura 8). Esse Porto presta serviços de logística para a importação e exportações de mercadorias manufaturadas, matérias primas e commodities no estado de Goiás, sendo um dos principais portos secos do interior do Brasil. Esse equipamento ratifica a dinâmica nas relações do município de Anápolis com o Brasil e com o mundo, operando em escala regional, nacional e global.

O porto atua em articulação com a Ferrovia Centro-Atlântica, ligada ao Porto de Santos. É prevista a sua articulação com a Ferrovia Norte-Sul, que ligará Anápolis ao Porto de Itaqui em São Luís do Maranhão. O pátio de manobras dessa ferrovia também está sendo 
CARDOSO JUNIOR, H. M.

Densidades do território em Anápolis - Goiás: notas sobre o trevo sul da Avenida Brasil

estruturado às margens do Porto Seco, sendo prevista sua integração com o modal aéreo e rodoviário.

Figura 8: Porto Seco Centro-Oeste e Pátio de Manobras da Ferrovia Norte-Sul (em construção) - Anápolis (GO) - 2015

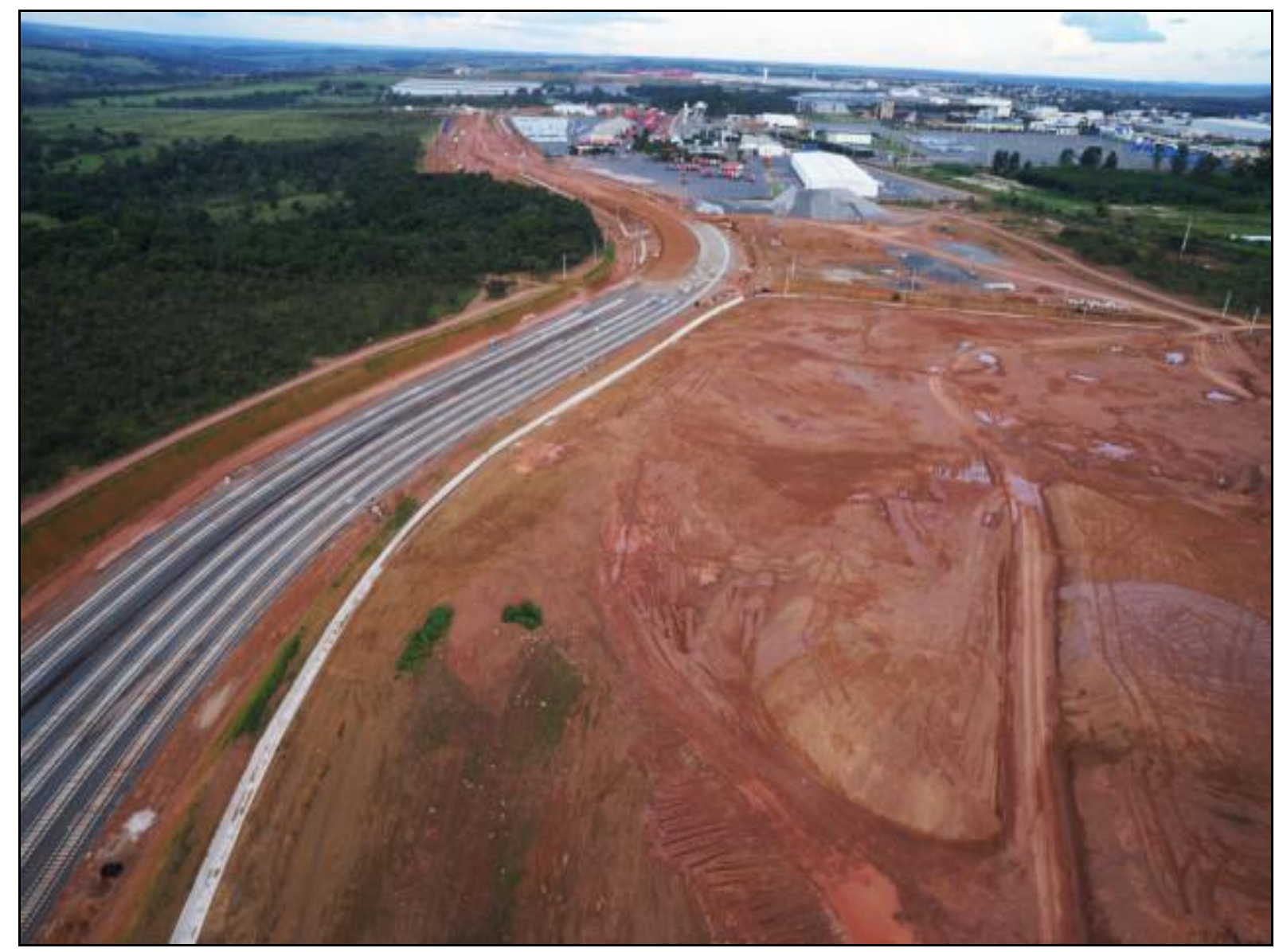

Fonte: AnápolisBrasil.com. Disponível em: <http://www.anapolisbrazil.inf.br/>. Acessado em: outubro de 2015.

$\mathrm{O}$ quarto eixo refere-se à $\mathrm{BR}$ - 060/153 sentido norte, partindo do viaduto. O sentido é em referência a Brasília. Pôde-se perceber a presença de diversos bairros residenciais, na porção oeste da rodovia, e de indústrias, na porção leste. Destacam-se como principais equipamentos desses eixos o Campus da Universidade Estadual de Goiás (Universidade Pública) e a Faculdade Fibra (Faculdade Particular) (Figura 9), importantes na articulação regional do município. 
CARDOSO JUNIOR, H. M.

Densidades do território em Anápolis - Goiás: notas sobre o trevo sul da Avenida Brasil

Figura 9: Universidade Estadual de Goiás e Faculdade FIBRA - Anápolis (GO) - 2015

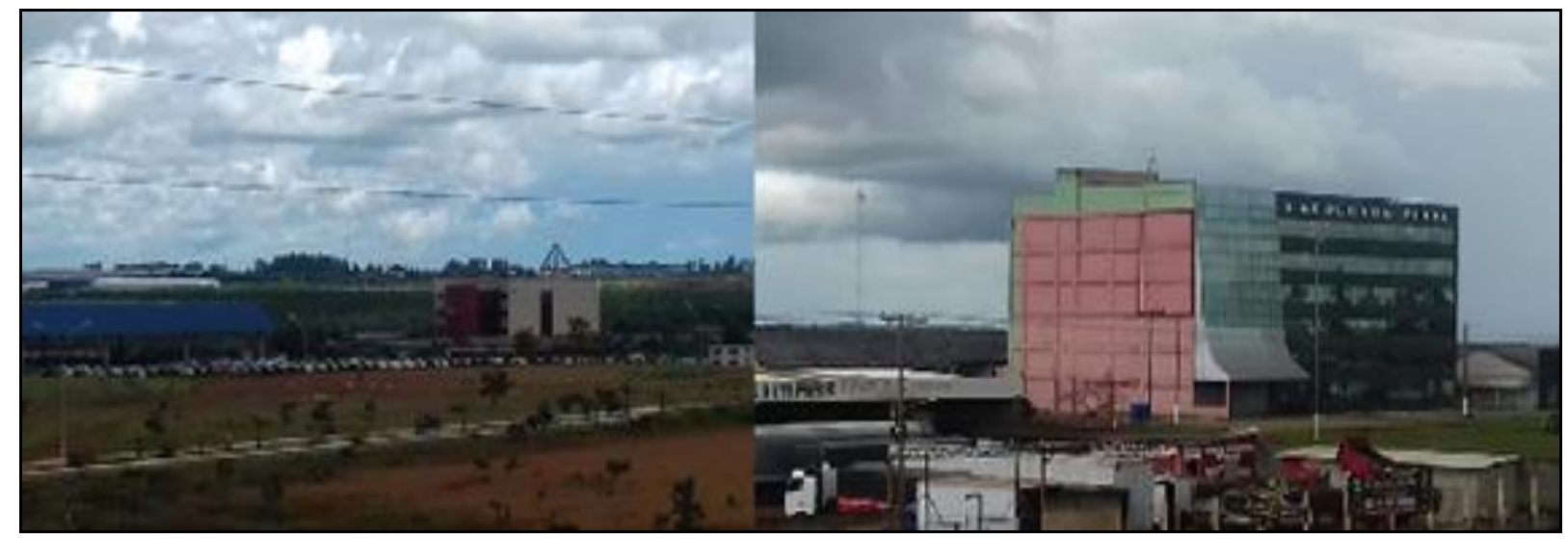

Fonte: Fotos tiradas pelo autor.

Ambas as universidades recebem alunos não só de Anápolis, mas da região, como: municípios do Norte do estado; Região Metropolitana de Goiânia e Região Integrada de Desenvolvimento Econômico de Brasília. Nas proximidades dessas duas Instituições de Ensino Superior pôde-se perceber a presença de um grande número de quitinetes, casas residenciais e barracões ${ }^{5}$ que são alugados exclusivamente para estudantes.

\section{AS DENSIDADES DO TERRITÓRIO E A QUESTÃO DO HABITAR}

Após a realização do trabalho de campo e do relato das impressões obtidas, esta seção traça uma análise do objeto estudado por meio da aplicação de três conceitos considerados importantes para o estudo do espaço na contemporaneidade, identificando as interações multiescalares de Anápolis e, dessa forma, analisar a questão do habitar na cidade capitalista: densidade técnica; densidade normativa e circuitos espaciais de produção e cooperação no espaço.

De acordo com o IBGE a cidade de Anápolis pode ser classificada como média levando em consideração seu contingente populacional ${ }^{6}$. Todavia, Sposito (2009, p. 13-14) chama a atenção para que é necessário "[...] empreender um esforço para superar a adoção

\footnotetext{
${ }^{5}$ Barracões são casas construídas de alvenaria que apresentam poucas repartições em seu interior (geralmente um quarto, sala, cozinha e banheiro). Sua principal característica é a construção em "meia água", ou seja, possui a metade de uma edificação básica comum. Podem ser construídos vários em um único lote.

${ }^{6}$ Para França (2007, p. 51) "para o Instituto Brasileiro de Geografia e Estatística - IBGE -, a cidade média é aquela que possui população entre 100.000 e 500.000 habitantes."
}

Revista Cerrados, Montes Claros/MG, v.17, n. 2, p. 265-289, jul./dez.-2019. 
Densidades do território em Anápolis - Goiás: notas sobre o trevo sul da Avenida Brasil

desses adjetivos de pequenas e médias, cidades pequenas e cidades médias, uma vez que não são suficientes para caracterizar as cidades não metropolitanas".

Para a autora a utilização apenas do critério populacional é insuficiente, pois é raso no processo de compreensão dos diferentes papéis que as cidades desempenham na divisão territorial do trabalho, bem como no cenário que se inserção nas redes e sistemas urbanos. Nesse sentido, além dos elementos quantitativos, é necessário considerar também os elementos qualitativos, os quais se propôs analisar nesta pesquisa com intuito de compreender melhor as interações estabelecidas por Anápolis com os diferentes pontos do território.

São esses elementos que possibilitaram, também, pensar o conceito do habitar. A questão do habitar na cidade foi pensada de diferentes formas. Di Felice (2009), afirma que o ambiente e o sujeito não estabelecem relações dicotômicas, mas que essas se dão de forma sistêmica. Nesse sentido, o pensador coloca que o ambiente e o sujeito se comunicam de forma incessante, modificando um ao outro.

Heidegger (2011) também ratifica essa afirmação ao entender que o espaço e o sujeito não estabelecem uma relação dialética, mas que ambos exercem forte influência um sobre o outro. Para o autor, pensar o habitar transcende pensar relações do sujeito com a casa, estendendo-se as reflexões a todos os espaços que o homem apropria-se.

De acordo com Lefebvre (2011) o principal espaço de ação do homem contemporâneo é a cidade. É importante que a ação do habitar permita a apropriação das potencialidades dos chamados territórios simbólicos que, na verdade, são produtos coletivos que estão em constante construção e permeados de relações afetivas e de poder (SANTOS, 1996). Portanto, pensar o habitar na cidade contemporânea é compreender tudo aquilo que o território disponibiliza que permite a produção/apropriação/vivência do urbano.

Destarte, é necessário pensar as densidades técnicas que fazem parte do cotidiano da cidade e que a conectam de forma multiescalar. Essas densidades derivam da dispersão das atividades econômicas no espaço, especialização do serviço (terceirização); complexificação das empresas; serviços integrados informativamente; surgimento de uma elite especializada e pela soberania das redes de empresas no mercado, características dadas pelo processo de globalização (SPOSITO, 2004).

Esse processo nas cidades resulta, como nos aponta Sposito (2012), numa reestruturação nas relações entre elas. A autora aponta dois pontos: a intensificação das relações entre redes urbanas distintas, de um lado; a interação espacial entre cidades de Revista Cerrados, Montes Claros/MG, v.17, n. 2, p. 265-289, jul./dez.-2019. 
CARDOSO JUNIOR, H. M.

Densidades do território em Anápolis - Goiás: notas sobre o trevo sul da Avenida Brasil

diferentes redes urbanas, de outro lado. A gradativa mundialização da produção, da pressão pelo consumo e do oferecimento de serviços, coloca a produção do espaço como um processo cada vez mais complexo. Parte-se da concepção de que a tão discutida globalização não teria se estruturado sem a consolidação da uma esfera geográfica material e normativa.

Nesse novo contexto da produção e reprodução espacial, que leva ao aprofundamento da divisão territorial do trabalho, à especialização regional produtiva e à racionalidade no movimento das mercadorias e informações, estruturam-se os circuitos espaciais de produção e os círculos de cooperação no espaço (SANTOS, 1986; SANTOS; SILVEIRA, 2001), que terão a densidade técnica e normativa como pressupostos essenciais.

Portanto, as grandes corporações ganham papel protagonista na articulação entre os lugares. Nesse processo, a logística apresenta-se como fundamental na manutenção da hegemonia da circulação de mercadorias, tornando-se estratégica a dotação do território, pelos agentes hegemônicos e pelo Estado, de aparelhos técnicos (sistemas de engenharia) que sejam capazes de garantir a fluidez de mercadorias, pessoas e informações. Milton Santos (1996) afirma que:

Uma das características do mundo atual é a emergência da fluidez para a circulação de ideias, mensagens, produtos ou dinheiro, interessando aos atores hegemônicos. A fluidez contemporânea é baseada nas redes técnicas, que são um dos suportes da competitividade. Dai a busca voraz de ainda mais fluidez, levando a procura de novas técnicas ainda mais eficazes. A fluidez é, ao mesmo tempo, uma causa, uma condição e um resultado (SANTOS, 1997, p. 185).

Dessa forma, levando em consideração a circulação como uma etapa imprescindível da produção, o território é aparelhado por equipamentos técnicos em busca da substituição da viscosidade do território por sua fluidez, já que o "produto está realmente acabado quando está no mercado" (MARX apud HARVEY, 2005). Nesse sentido, este processo demanda investimentos em objetos (fixos) que permitem a realização dos fluxos, como aponta Arroyo (2001).

Milton Santos (1996) ainda afirma que os espaços de globalização tendem a apresentar conteúdos de densidades técnicas distintas, pois essas densidades satisfazem às necessidades particulares dos diferentes agentes hegemônicos. Segundo o autor:

A densidade técnica é dada pelos diversos graus de artifício. As situações-limite seriam, de um lado, uma área natural jamais tocada pelo homem - uma ecologia selvagem - e, de outro lado, uma área onde houvesse apenas aquilo a que SIMONDON (1958) chamou de objetos técnicos maduros, como no centro de 
CARDOSO JUNIOR, H. M.

Densidades do território em Anápolis - Goiás: notas sobre o trevo sul da Avenida Brasil

negócios de uma grande cidade, onde espaços inteligentes são dispostos para atender prontamente às intenções dos que os conceberam e produziram, objetos muito mais perfeitos que a própria natureza. (SANTOS, 1997, p. 173)

Portanto, as políticas públicas e privadas passam a incorporar, então, a necessidade de novas densidades técnicas e normativas (SILVEIRA, 2004) para promover a criação de novas possibilidades de incorporação do território pelo capital. A construção de grandes sistemas de engenharia, como o viaduto, a ferrovia norte-sul, o Porto Seco e as rodovias e avenidas analisadas neste estudo representam o aparelhamento técnico do território com o intuito de assegurar as necessidades de acumulação e reprodução do capital, principalmente o industrial. Nesse sentido, a questão do habitar, na área de estudo, passa pela densidade técnica, que se territorializa de forma diferenciada, indo ao encontro com a satisfação das necessidades dos agentes do capital territorializados nessa área da cidade.

$\mathrm{Na}$ área analisada pôde-se perceber a presença de uma densidade técnica voltada para os processos produtivos (indústrias), assegurando o fluxo tanto de mercadorias quanto de matérias primas. O DAIA representa uma grande estrutura voltada à produção de bens de consumo, concentrando densidade técnica nos processos de produção (automação do processo produtivo), bem como uma densidade técnica que garanta o fluxo de suas trocas, a destacar:

- Porto Seco Centro-Oeste - garante o transporte de mercadorias em escala nacional e internacional, transportando não apenas os bens produzidos no DAIA, mas também minérios da região norte de Goiás e commodities agrícolas do sul do estado para diferentes mercados consumidores;

- As rodovias - importantes eixos de integração com o norte e sul do país, bem como do Eixo Goiânia-Anápolis-Brasília;

- O viaduto da saída sul - importante nó de fluxo que garante a livre circulação entre as rodovias que o cortam e entre o fluxo de pessoas e trabalhadores na cidade de Anápolis;

- Centro de Convenções - estrutura que, quando concluída, servirá a reuniões, eventos e feiras, permitindo a troca de relações em favor do uso, principalmente, do capital.

A Avenida Brasil Sul também tende a concentrar densidade técnica. Sua própria estrutura, larga e com várias faixas de acesso garantem a fluidez de pessoas, mercadorias e 
Densidades do território em Anápolis - Goiás: notas sobre o trevo sul da Avenida Brasil

informações. A presença de atacadistas e a recente construção de hotéis e concessionárias ratificam a afirmação. Essas densidades técnicas consolidam as relações dessa área, e do município, com as escalas regionais, nacional e global.

Portanto, a área de estudo possui elevada densidade técnica implantada de acordo com os interesses do empresariado. As vias de transporte como as rodovias, ferrovias, bem como o futuro aeroporto de cargas, além da Avenida Brasil Sul tem como objetivo conectar a produção de bens de consumo produzidos pelas indústrias nesse ponto do território, no Distrito Agroindustrial e arredores, com os mercados consumidores do Brasil e do exterior, do mesmo modo que permite o transporte de trabalhadores para o parque industrial.

A presença de um parque industrial altamente automatizado (o DAIA), com uso de técnicas modernas, e a presença de redes de comunicação que permitem o estabelecimento de relações das indústrias sediadas em Anápolis, mais especificamente na área analisada, completam a densidade técnica presente nesse ponto da cidade.

Além da densidade técnica, a área analisada também apresenta uma elevada densidade normativa. Segundo Silveira (1997), o território hoje é povoado por objetos técnicos perfeitos que se destinam a atender necessidades e limites precisos. No atual contexto, os lugares estão em constante transformação, acolhendo continuamente novos objetos e novas formas organizacionais, que resultam na alteração do valor das normas vigentes.

Silveira (1997) apresenta três elementos que integram os modos de regulação no período técnico-científico-informacional: normas técnicas; normas organizacionais e normas políticas. Quanto ao primeiro, normas técnicas, a autora aponta que a técnica, atualmente, é constantemente normatizada, “[...] pois a precisão dos objetos impõe uma forma de operá-los e chama a novas solidariedades técnicas”. Portanto, as normas técnicas serão substituídas na mesma velocidade que os objetos técnicos são alterados, à medida que se tornam arcaicos.

A operação dos objetos técnicos, que se apresentam na atualidade altamente especializados, é garantida pela determinação, simultânea, de normas técnicas rígidas que visam assegurar a fluidez do espaço. Nesse sentido, a norma técnica assume um papel, como aponta Silveira (1997), de homogeneização dos processos técnicos a qual normatiza.

Quanto ao segundo elemento, normas organizacionais, a autora aponta que são responsáveis por regular a utilização dos novos objetos técnicos nos processos de trabalho. 
CARDOSO JUNIOR, H. M.

Densidades do território em Anápolis - Goiás: notas sobre o trevo sul da Avenida Brasil

Elas regulam as relações que uma organização quer manter com outras organizações, com o consumidor e com seus trabalhadores, sempre em busca de criar uma fluidez nas relações.

Quando às duas normas apresentadas, Silveira (2004) afirma que:

[...] essas normas são, também, novos princípios de regulação técnica, constituindose em verdadeiras formas de hibridação normativa. De tal maneira, elas contribuem na produção de novos arranjos espaciais de alto conteúdo informacional e comunicacional (SILVEIRA, 2004, p. 39).

Por fim, a autora apresenta as normas políticas. Segundo ela, essas normas englobam as relações de cooperação e disputa entre o Estado e o mercado. São as diretrizes e regras estabelecidas pelo Estado para a regulação do mercado. Segundo Silveira (1997), no atual contexto de liberação econômica que privilegia a ampliação dos fluxos transnacionais de capital, as normas políticas tendem a flexibilizar as ações dos agentes da globalização.

A densidade normativa, assim como a técnica, também se faz presente no habitar da área estuda. A produção e a reprodução do urbano no objeto de estudo destacado, levando em consideração que a produção e o transporte de mercadorias são importantes fatores multiplicadores do crescimento nessa área da cidade, também estrutura-se na densidade normativa. Exemplificando, podem-se destacar as empresas multinacionais e transnacionais presentes no DAIA que possuem seus processos produtivos regulados por normas técnicas mundiais como o ISO 9001, que garante a certificação dessas empresas nos temas de saúde, meio ambiente e segurança, bem como selos ecológicos em nível nacional e global.

Essas empresas também estão submetidas às normas organizacionais que garantem suas relações com os consumidores e parceiros, bem como o estabelecimento de novas relações contratuais. Como exemplo pode-se destacar a prática do just-in-time, um sistema de produção que tem como objetivo reduzir stocks, produzindo nada além do necessário. Esse sistema possibilita o fornecimento de mercadorias em tempo real (por encomenda) muito utilizado na atualidade por grandes indústrias e atacadistas. Por fim, as normas políticas também se fazem presentes. O Estado coopera de forma ativa, uma vez que não é um agente mediador neutro, pois age em favor dos grupos dominantes, permitindo que as operações transnacionais se expandam (SILVEIRA, 1997).

As isenções fiscais, a presença da Goiás Industrial e do Programa Fomentar, a concessão de atividades ao Porto Seco Centro-Oeste, a desregulamentação da economia e a flexibilização das relações de trabalho por meio da terceirização sob a tutela do Estado garantem a expansão dos agentes hegemônicos presentes na área estudada. 
Densidades do território em Anápolis - Goiás: notas sobre o trevo sul da Avenida Brasil

As densidades técnicas, automação dos processos produtivos e objetos técnicos que garantem a fluidez (obras de engenharia; sistemas de comunicação), bem como as densidades normativas, diretrizes e normas estabelecidas pelos agentes hegemônicos e pelo Estado, possibilitam que os centros de produção se distanciem espacialmente cada vez mais de seus centros consumidores, resultando numa crescente especialização produtiva dos espaços, tornando cada vez mais complexa a distribuição espacial das atividades econômicas.

Nesse contexto, estruturam-se os circuitos espaciais de produção e os círculos de cooperação no espaço. Segundo Moraes (1985, p. 156) “[...] discutir os circuitos espaciais da produção é discutir a espacialidade da produção-distribuição-troca-consumo como movimento circular constante". Nesse sentido, a autora coloca o espaço como um elemento importante a ser considerado, pois é nessa categoria que se estruturará os circuitos (circulação) da produção.

A circulação é elemento chave na estruturação dos circuitos espaciais de produção, que são "[...] definidos pela circulação de bens e produtos e, por isso, oferecem uma visão dinâmica, apontando como os fluxos perpassam o território" (SANTOS e SILVEIRA, 2011, p. 143). Como se pôde perceber anteriormente, as formas com conteúdos funcionais estruturadas no espaço atenderam a interesses dos atores hegemônicos do capital, possibilitando a estruturação de diferentes circuitos espaciais de produção no espaço, onde coexistiram formas com racionalidades e conteúdos diferentes, implantadas em períodos distintos. Nesse sentido, o espaço geográfico é reconhecido pela acumulação desigual de tempos (SANTOS, 1996).

Arroyo aponta que os circuitos espaciais de produção são formados por empresas de diferentes ramos e tamanhos. Segundo a autora, a "[...] articulação se expressa pelo movimento de inúmeros fluxos de produtos, ideias, ordens, informações, dinheiro, excedente" (ARROYO, 2001, p. 30). As diferentes etapas do processo de produção capitalista estão cada vez mais dispersas no espaço. Fornecedores de matérias primas; plantas industriais de transformação da matéria ou montagem dos produtos e os mercados consumidores não necessitam estar espacialmente próximos para o sucesso do processo de acumulação capitalista. Entretanto, essas diferentes etapas estão cada vez mais articuladas pelas redes técnicas que permitem a comunicação e a troca de informações.

Esse fato torna claro que no espaço não se realiza a circulação apenas de fluxos materiais, mas também de fluxos imateriais. Nesse sentido, veem-se como importantes os 
CARDOSO JUNIOR, H. M.

Densidades do território em Anápolis - Goiás: notas sobre o trevo sul da Avenida Brasil

círculos de cooperação no espaço. Segundo Santos e Silveira (2011), esses círculos podem ser entendidos como as relações estabelecidas entre os lugares e os agentes (corporações), que são possibilitadas pelos sistemas técnicas de comunicação que realizam as trocas de informações. Portanto, os círculos de cooperação no espaço são de suma importância para a articulação das diferentes etapas de produção, conectando os diferentes agentes com os diferentes lugares que compõem o circuito espacial de produção.

Segundo Castilho e Frederico (2010, p. 464): “As noções de circuito espacial da produção e de círculos de cooperação no espaço permitem verificar a interdependência dos espaços produtivos, captando a unidade e a circularidade do movimento". Os círculos espaciais de produção na área analisada se traduzem nas trocas materiais (fluxos materiais) entre as diferentes etapas (produção, distribuição, troca e consumo) do processo de produção de um produto, que se encontram separadas geograficamente. Já os círculos de cooperação no espaço são as trocas imateriais, fluxos imateriais (informações, dinheiro, ideias, mensagens) estabelecidos entre as indústrias, atacadistas e transportadoras presentes no DAIA e seus mercados consumidores, fornecedores de matérias primas e centros de comando (sedes administrativas).

Esses círculos de cooperação no espaço articulam as diferentes etapas da produção capitalista, de forma centralizada, e conectam os agentes hegemônicos presentes na área analisada (indústrias, principalmente) aos lugares. Ambos são possibilitados pelo aparelhamento do território por sistemas de engenharia e redes de comunicação. As diversas empresas instaladas na área estudada estruturam seus circuitos espaciais de produção em diferentes escalas, a depender de seu mercado consumidor, seus parceiros comerciais, e de seu ramo de atuação. Do mesmo modo, os círculos espaciais de cooperação se fazem presentes nas redes de comunicação que estruturam as trocas imateriais entre a área analisada e os pontos necessários para a realização de suas atividades.

Não será destacado aqui o circuito espacial de produção de cada empresa, mas com a inserção desse conceito nesta análise é possível apontar que as relações e interações desse ponto do território de Anápolis se dão, de forma intensa e complexa, nas escalas regional, nacional e global. Dessa forma, observa-se que há uma verticalização do território por meio das estruturas administrativas e de produção presentes na área estudada. Por meio dessa estrutura essas empresas apropriam-se das potencialidades locacionais, das 
CARDOSO JUNIOR, H. M.

Densidades do território em Anápolis - Goiás: notas sobre o trevo sul da Avenida Brasil

infraestruturas e dos incentivos estatais presentes no município de Anápolis, ampliando suas áreas de atuação e maximizando o lucro.

Essas empresas realizam o uso corporativo do território, controlando e dominando o espaço por meio de relações capitalistas que são dadas pelos fluxos materiais (circuito espacial da produção) e interconectadas por fluxos imateriais (círculos de cooperação no espaço) e ocorrem em escala global.

\section{CONSIDERAÇÕES FINAIS}

O estudo apresentou análises de um trabalho de campo realizado em um ponto da cidade de Anápolis, estado de Goiás, no ano de 2015. As observações, com base nos conceitos definidos para o estudo, demonstram que a questão do habitar no município, cidade média e industrial, está permeada pela presença de uma densidade técnica e normativa no território.

Os equipamentos urbanos e as transformações na infraestrutura observadas no recorde apresentado são capazes de redefinir a relação do habitar do homem e o espaço urbano. As universidades, as indústrias, as rodovias, o porto seco e o Centro de Convenções, bem como outros equipamentos e estabelecimentos destacados, são responsáveis por estabelecer relações multiescalares de Anápolis com outros pontos do território.

A questão do habitar no recorte espacial é definida pelo consumo e produção de mercadorias, relacionando o território à organização espacial da produção. Os efeitos multiplicadores do crescimento capitalista articulam, por meio dos agentes hegemônicos e do Estado, esse território com as escalas regional, nacional e global, redefinindo as relações do homem com o espaço urbano.

As densidades observadas são resultado do uso corporativo do território, baseado nos interesses das grandes empresas instaladas na área analisada que tem o Estado como uma instituição garantidora de suas atividades seja pela manutenção de instituições cientificas, espaços públicos construídos, prioritariamente, para o uso do capital, como o Centro de Convenções, ou infraestrutura necessária para escoamento da produção nos diferentes modais logísticos.

Por fim, o habitar ocorre em meio à cidade que intensifica a divisão social do trabalho, se comunica não mais apenas em redes, mas em um sistema urbano e que se Revista Cerrados, Montes Claros/MG, v.17, n. 2, p. 265-289, jul./dez.-2019. 
CARDOSO JUNIOR, H. M.

Densidades do território em Anápolis - Goiás: notas sobre o trevo sul da Avenida Brasil

encontra em constante transformação/produção em meio ao habitar (vida) permeada pelos objetos de consumo.

\section{REFERÊNCIAS}

ANTUNES, M.; MELLO, M. de; ARRAIS, T. A. O entorno do Distrito Federal: nota exploratório de um trabalho de campo. Boletim Goiano de Geografia. v. 27, n. 3, p. 145$150,2007$.

ARROYO, M. M. Território Nacional e Mercado Externo: uma leitura do Brasil na virada do século XX. 2001. 250 f. Tese (Doutorado em Geografia Humana) - Departamento de Geografia, Faculdade de Filosofia, Letras e Ciências Humanas, Universidade de São Paulo (USP), São Paulo - SP, 2001.

BRANDÃO, Z. Entre questionários e entrevistas. In: NOGUEIRA, M. A.; ROMANELLI, G.; ZAGO, N. (orgs.). Família \& escola. Rio de Janeiro: Vozes, p. 171-83, 2000.

BRASIL. Instituto Brasileiro de Geografia e Estatística (IBGE). Produto Interno Bruto dos Municípios 2012. Rio de Janeiro, 2014.

BRASIL. Instituto Brasileiro de Geografia e Estatística (IBGE). Atlas do Censo Demográfico 2010. Rio de Janeiro, 2013.

CASTILLO, R.; FREDERICO, S. Dinâmica regional e globalização: Espaços competitivos agrícolas no território brasileiro. Mercator, v. 9, número 18, p. 17-26, jan./abr. 2010.

DI FELICE, M. Paisagens Pós-Urbanas: o fim da experiência urbana e as formas comunicativas do habitar. São Paulo (SP): Annablume, 2009.

GOIÁS. Companhia de Desenvolvimento Econômico de Goiás (CODEGO). Distrito Agroindustrial de Anápolis. Disponível em: < http://www.goiasindustrial.com.br/distritosin dustriais/?distrito=4>. Acessado em: dezembro de 2015.

FRANÇA, I. S. de. A cidade média e suas centralidades: o exemplo de Montes Claros no norte de Minas Gerais. 2007. 240f. Dissertação (Mestrado em Geografia) - Universidade Federal de Uberlândia, 2007.

HARVEY, D. A diferença que faz uma geração. In: Espaços de Esperança. São Paulo (SP): Loyola, p. 15-33, 2004

HARVEY, D. A Produção Capitalista do Espaço. São Paulo: Annablume, 2005.

HEIDEGGER, M. Ser e tempo. 5 ed. Petrópolis (RJ): Vozes, 2011. 
CARDOSO JUNIOR, H. M.

Densidades do território em Anápolis - Goiás: notas sobre o trevo sul da Avenida Brasil

IBGE. Instituto Brasileiro de Geografia e Estatística - Sistema de Recuperação Automática (SIDRA). Rio de Janeiro: IBGE, 2016. Disponível em:

<https://sidra.ibge.gov.br/home/ipca/brasil>. Acessado em: dezembro de 2016.

LEFEBVRE, H. O direito à cidade. 5 ed. São Paulo (SP): Centauro, 2011.

MORAES, A. C. R. de. Los circuitos espaciales de la producción y los círculos de cooperación em el espacio. In: Yanes, L. et all (org.). Aportes para el estúdio del espacio socioeconômico, Tomo II, El Colóqio, Buenos Aires, 1985.

PEIXOTO, E. R. A cidade genérica. Revista Estudos, Goiânia, v.31, n.10, p. 1993-2018, nov., 2004.

SANTOS, M.; SILVEIRA, M. L. O Brasil: território e sociedade no início do século XXI. São Paulo: Record, 2001.

SANTOS, M. A natureza do espaço: técnica e tempo, razão e emoção. São Paulo: Hucitec, 1996.

SANTOS, M. Circuitos espaciais de produção: um comentário. In: SOUZA, M. A. A.; SANTOS, Milton (Orgs.). A construção do espaço. São Paulo: Nobe, p. 121-134, 1986.

SILVEIRA, M. L. Escala geográfica: da ação ao império? Revista Terra Livre, Goiânia, ano 20, v. 2, n. 23, p. 87-96, 2004.

SILVEIRA, M. L. Concretude territorial, regulação e densidade normativa. In: Revista Experimental. São Paulo: Laboplan - Departamento de Geografia da Faculdade de Filosofia, Letras e Ciências Humanas da Universidade de São Paulo, n. 02, p. 35-45, março de 1997

SPOSITO, M. E. B.; CARLOS, Ana. Fani Alessandri; SOUZA, Marcelo Lopes (orgs.). A produção do espaço urbano: Agentes e processos, escalas e desafios. São Paulo (SP): Contexto, 2012.

SPOSITO, M. E. B. Novos conteúdos nas periferias urbanas nas cidades médias do estado de São Paulo, Brasil. Revista Investigaciones Geográficas, Boletín del Instituto de GeografiaUNAM, Cidade do México, n.54, p. 114-139, 2004.

SPOSITO, M. E. B. Para pensar as pequenas e médias cidades brasileiras. Belém: FASE/ICSA/UFPA, 2009. 
Hamilton Matos Cardoso Júnior - Possui Graduação em Geografia e Mestrado em Territórios e Expressões Culturais no Cerrado, ambos cursados pela Universidade Estadual de Goiás (UEG). Atualmente é Técnico em Assuntos Educacionais na Universidade Federal da Paraíba (UFPB).

Artigo recebido em: 28 de julho de 2019.

Artigo aceito em: 10 de outubro de 2019.

Artigo publicado em: 20 de dezembro de 2019. 